\title{
The Accuracy of Magnetic Resonance Imaging in Radical Prostatectomy
}

\author{
Qayyum T. ${ }^{\mathrm{a}} \quad$ Willder J.M. ${ }^{\mathrm{a}} \quad$ McArdle P.A. ${ }^{\mathrm{b}}$ \\ Horgan P.G.c Edwards J. ${ }^{a} \quad$ Underwood M.A. ${ }^{b}$ \\ aUnit of Experimental Therapeutics, Institute of Cancer, College of MVLS, University of Glasgow, Western Infirmary; \\ bDepartment of Urology, Royal Infirmary; 'School of Medicine, College of MVLS, University of Glasgow, Royal Infirmary, Glasgow, UK
}

\section{Key Words}

Magnetic resonance imaging • Prostate cancer •

Prostatectomy

\begin{abstract}
Aims: The aim of this study was to examine the accuracy of standard magnetic resonance imaging (MRI) in the localised staging of prostate cancer in those who had undergone radical prostatectomy. Patients and Methods: The cohort consisted of 110 patients who had undergone MRI for staging of prostate cancer and subsequently underwent radical prostatectomy. T stage was analysed both on MRI and from the specimen following radical surgery. Results: Of the patients $57 \%$ of patients had their disease up-staged following radical surgery from preoperative MRI findings. Of those patients who had their disease up-staged following surgery, nearly $50 \%$ of patients had gone from organ confined disease at time of MRI to extra-prostatic involvement from the surgical specimen. Conclusion: We have reported that MRI has a wide range of accuracy. Given developments in MRI technologies further work should be pursued to help in the staging of this disease for which decision to treat is difficult.
\end{abstract}

Copyright $\odot 2013$ S. Karger AG, Basel

\section{KARGER}

Fax +4161306 1234

E-Mail karger@karger.ch

www.karger.com
(C) 2013 S. Karger AG, Basel

1015-9770/13/0072-0062\$38.00/0

Accessible online at:

www.karger.com/cur

\section{Introduction}

Prostate cancer is now recognised as a major burden on the global health-care system. In the United States and in Europe, it is the most common neoplasm diagnosed in men and is responsible for $11 \%$ of all male cancer deaths $[1,2]$. After a diagnosis of prostate cancer is made, a number of treatments may be considered depending on the information provided by staging investigations. In patients who are thought to have organ confined prostate cancer treatment options include radical prostatectomy, external beam radiation therapy, brachytherapy and active monitoring.

In those treated by radical prostatectomy, seminal vesicle involvement (SVI) or extracapsular extension (ECE) are often associated with recurrent disease [3]. It is therefore of the upmost importance that imaging modalities are able to detect this accurately prior to surgery. When radical surgery is contemplated, computed tomography (CT) and/or magnetic resonance imaging (MRI) are utilised to stage the disease to ensure it is organ confined. Imaging evaluation of the prostate is challenging given tissue heterogeneity $[4,5]$.

Transrectal ultrasound (TRUS) is the most common modality used when imaging the prostate but is associated with the disease being under-staged [6]. This modality can only detect $50 \%$ of cancers due to tumor heterogeneity and it has been suggested that TRUS in combination with digital rectal examination can more accurately detect T3a tumors than either method alone [7] but despite this $60 \%$ of T3a tumors will not be detected by

Tahir Qayyum

Institute of Cancer, College of MVLS

University of Glasgow, Western Infirmary

G11 6NT Glasgow (UK)

E-Mail tahir1@ doctors.org.uk 
TRUS alone [8]. The rate of detection of cancers can be increased by using color doppler [9-11] with some suggesting that it can optimise the number of biopsies taken [12]. In those with a new diagnosis of prostate cancer, it has been suggested that Gleason grade, prostate specific antigen and clinical stage are independent predictors of a CT scan being positive for metastases and therefore patients with low risk need not have a CT scan [13] but it is in this cohort that radical surgery maybe contemplated and therefore it is of upmost importance that all information about any possibility of local invasion is available before a treatment path is chosen. Currently MRI is used to detect evidence of ECE or SVI with a tendency to over-stage disease [6]. It has been suggested that MRI is cost effective [14]. In comparison to digital rectal examination, TRUS and CT, MRI has a higher accuracy in the assessment of unilateral or bilateral disease, ECE and SVI as well as the invasion of adjacent structures [15]. In cases of planning treatment with external beam radiotherapy, it has been reported that MRI provides more detailed information than CT when utilised as a radiotherapy tool [16]. Despite this, literature would suggest that there is a wide range in the accuracy of local staging (50-90\%) [17]. Endorectal MRI (eMRI) has been suggested to be more accurate than conventional MRI in terms of localisation of the cancer predicting SVI and ECE [18-20] but in analysing previous data [20] it has been shown that this increased accuracy was only significant when eMRI was performed by genitourinary radiologists with substantial experience [21]. It has also been reported that eMRI has a sensitivity of $69 \%$ and specificity of $90 \%$ for the identification of ECE [22].

The aim of this study was to examine the accuracy of standard MRI in the localised staging of prostate cancer in those who had undergone radical prostatectomy.

\section{Patients and Methods}

Patients diagnosed with prostate cancer following TRUS guided biopsy in North Glasgow NHS Trust and who subsequently underwent radical prostatectomy were included. Patients were staged according to the TNM classification both on radiological imaging which was MRI and after the radical specimen was analysed. The Research Ethics Committee of North Glasgow NHS Trust approved the study.

All patients underwent a standard MRI based on local protocol for imaging for prostate cancer after initial diagnosis. One institution was involved with undertaking the MRI. Consultant radiologists with sub-speciality interest in urology undertook reporting the MRI. All surgery was performed by one unit at the Royal Infirmary.

Magnetic Resonance Imaging in Radical Prostatectomy

\section{Results}

One hundred and ten patients were studied for whom all clinical data was available and had undergone radical prostatectomy. Median age of diagnosis was 61 years (range 43-73 years). Median time from MRI until surgery was 87 days. Of the cohort, $2 \%$ of patients were on active surveillance prior to radical prostatectomy.

Of all patients, only $27 \%(n=30)$ showed no difference between radiological and pathological staging, 57\% $(n=63)$ were up-staged after surgery and $16 \%(n=17)$ had their disease from their MRI after surgery downstaged. Nearly $50 \%(n=30)$ of those patients that were up-staged after surgery had gone from organ confined disease to ECE or SVI.

In this sub-group of patients that were up-staged after surgery, the median time from MRI imaging until surgery was 64 days whilst in comparison for all patients the median time from MRI until surgery was 87 days.

When assessing the Gleason sum of both tissue at time of TRUS and from the radical specimen, $42 \%$ ( $\mathrm{n}=$ 46) had the Gleason sum increased after radical surgery was performed possibly indicating aggressive disease. Of these patients, $61 \%(n=28)$ were up-staged on the basis of MRI and radical surgery.

\section{Discussion}

Results from the present study further reiterate the wide range of accuracy when assessing local staging for prostate cancer prior to radical surgery.

Previous reports have suggested that MRI has a tendency to over-stage disease $[6,23,24]$ but these are historical studies with MRI technology improving in recent years. Our findings have suggested that MRI not only does not over-stage disease but if anything under-stages disease. Even though the decision to pursue radical surgery does not solely rely on MRI findings, this presents a further dilemma if MRI is under-staging the disease. This may deter both surgeon and patient in pursuing radical surgery if the likelihood of cure is reduced and other treatment options would need to be considered. The upstaging of cancer from MRI to the radical specimen could be accounted due to $61 \%$ of these patients had an increase in the Gleason sum form initial diagnosis to the radical specimen therefore suggesting aggressive disease.

The accuracy of MRI for staging purposes of prostate cancer varies from 50 to $90 \%$ [17,21]. Despite this variability it is still utilised for staging purposes and detec-

Curr Urol 2013;7:62-64 
tion of recurrence. It has been reported that preoperative findings at MRI can be utilised as a strong predictor of biochemical recurrence [25] and that these findings can be utilised to predict relapse following external beam radiotherapy treatment [26]. It has been recently reported that MRI has a higher sensitivity (93\%) for high grade tumors than low grade tumors (68\%) [27] and therefore MRI would aid in those that would benefit most from surgery.
We have reported that MRI has a wide range of accuracy in staging prostate cancer in a cohort of patients that have undergone radical surgery. Given advancements in MRI technologies, further work is required to assess the accuracy of this technology, especially in those who are undergoing radical treatment.

\section{References}

1 Jemal A, Siegel R, Xu J, Ward E: Cancer sta- 12 Sauvain JL, Palascak P, Nader N, Gomez W, tistics, 2010. CA Cancer J Clin 2010;60:277300.

2 Boyle P, Ferlay J: Cancer incidence and mortality in Europe, 2004. Ann Oncol 2005;16: 481-488.

3 Epstein JI, Pizov G, Walsh PC: Correlation of pathologic findings with progression after radical retropubic prostatectomy. Cancer 1993;71:3582-3593.

4 Oehr P, Bouchelouche K: Imaging of prostate cancer. Curr Opin Oncol 2007;19:259-264.

5 Fuchsjager M, Shukla-Dave A, Akin O, Barentsz J, Hricak H: Prostate cancer imaging. Acta Radiol 2008;49:107-120.

6 May F, Treumann T, Dettmar P, Hartung R, Breul J: Limited value of endorectal magnetic resonance imaging and transrectal ultrasonography in the staging of clinically localized prostate cancer. BJU Int 2001;87:66-69.

7 Hsu CY, Joniau S, Oyen R, Roskams T, Van Poppel H: Detection of clinical unilateral T3a prostate cancer - by digital rectal examination or transrectal ultrasonography? BJU Int 2006;98:982-985.

8 Enlund A, Pedersen K, Boeryd B, Varenhorst E: Transrectal ultrasonography compared to histopathological assessment for local staging of prostatic carcinoma. Acta Radiol 1990; 31:597-600.

-9 Sauvain JL, Palascak P, Bourscheid D, Chabi C, Atassi A, Bremon JM, Palascak R: Value of power doppler and 3D vascular sonography as a method for diagnosis and staging of prostate cancer. Eur Urol 2003;44:21-30.

10 Zalesky M, Urban M, Smerhovsky Z, Zachoval R, Lukes M, Heracek J: Value of power Doppler sonography with 3D reconstruction in preoperative diagnostics of extraprostatic tumor extension in clinically localized prostate cancer. Int J Urol 2008;15:68-75.

11 Zalesky M, Zachoval R, Smerhovsky Z, Lukes M, Heracek J, Vik V, Klemenc V, Urban M: Evaluation of the tumor extension before planned radical prostatectomy: a prospective study. Cas Lek Cesk 2007;146:793800. Bloqueau P, Bremon JM, Jung L, Maniere P, Papavero R: Power Doppler imaging and prostate cancer: optional or necessary technique? J Radiol 2006;87:1063-1072.

13 Lee N, Newhouse JH, Olsson CA, Benson MC, Petrylak DP, Schiff PB, Bagiella E, Malyszko B, Ennis RD: Which patients with newly diagnosed prostate cancer need a computed tomography scan of the abdomen and pelvis? An analysis based on 588 patients. Urology 1999;54:490-494.

14 Jager GJ, Severens JL, Thornbury JR, de La Rosette JJ, Ruijs SH, Barentsz JO: Prostate cancer staging: should MR imaging be used? - A decision analytic approach. Radiology 2000;215:445-451.

15 Hricak H: MR imaging and MR spectroscopic imaging in the pre-treatment evaluation of prostate cancer. Br J Radiol 2005;78(spec No 2):S103-S111.

16 Villeirs GM, De Meerleer GO: Magnetic resonance imaging (MRI) anatomy of the prostate and application of MRI in radiotherapy planning. Eur J Radiol 2007;63:361-368.

17 Engelbrecht MR, Jager GJ, Laheij RJ, Verbeek AL, van Lier HJ, Barentsz JO: Local staging of prostate cancer using magnetic resonance imaging: a meta-analysis. Eur Radiol 2002;12:2294-2302.

18 Wang L, Hricak H, Kattan MW, Chen HN, Kuroiwa K, Eisenberg HF, Scardino PT: Prediction of seminal vesicle invasion in prostate cancer: incremental value of adding endorectal MR imaging to the Kattan nomogram. Radiology 2007;242:182-188.

19 Sala E, Akin O, Moskowitz CS, Eisenberg HF, Kuroiwa K, Ishill NM, Rajashanker B, Scardino PT, Hricak H: Endorectal MR imaging in the evaluation of seminal vesicle invasion: diagnostic accuracy and multivariate feature analysis. Radiology 2006;238:929937.

20 Wang L, Mullerad M, Chen HN, Eberhardt SC, Kattan MW, Scardino PT, Hricak H: Prostate cancer: incremental value of endorectal MR imaging findings for prediction of extracapsular extension. Radiology 2004; 232:133-139.
21 Mullerad M, Hricak H, Wang L, Chen HN, Kattan MW, Scardino PT: Prostate cancer: detection of extracapsular extension by genitourinary and general body radiologists at MR imaging. Radiology 2004;232:140-146.

22 Wang L, Akin O, Mazaheri Y, Ishill NM, Kuroiwa K, Zhang J, Hricak H: Are histopathological features of prostate cancer lesions associated with identification of extracapsular extension on magnetic resonance imaging? BJU Int 2010;106:1303-1308.

-23 Rifkin MD, Zerhouni EA, Gatsonis CA, Quint LE, Paushter DM, Epstein JI, Hamper U, Walsh PC, McNeil BJ: Comparison of magnetic resonance imaging and ultrasonography in staging early prostate cancer. Results of a multi-institutional cooperative trial. N Engl J Med 1990; 323:621-626.

24 Presti JC Jr, Hricak H, Narayan PA, Shinohara $\mathrm{K}$, White S, Carroll PR: Local staging of prostatic carcinoma: comparison of transrectal sonography and endorectal MR imaging. AJR Am J Roentgenol 1996;166:103-108.

25 Fuchsjager MH, Shukla-Dave A, Hricak H, Wang L, Touijer K, Donohue JF, Eastham JA, Kattan MW: Magnetic resonance imaging in the prediction of biochemical recurrence of prostate cancer after radical prostatectomy. BJU Int 2009; 104:315-320.

-26 Fuchsjager MH, Pucar D, Zelefsky MJ, Zhang Z, Mo Q, Ben-Porat LS, Shukla-Dave A, Wang L, Reuter VE, Hricak H: Predicting post-external beam radiation therapy PSA relapse of prostate cancer using pretreatment MRI. Int J Radiat Oncol Biol Phys 2010;78: 743-750.

27 Villeirs GM, De Meerleer GO, De Visschere PJ, Fonteyne VH, Verbaeys AC, Oosterlinck $\mathrm{W}$ : Combined magnetic resonance imaging and spectroscopy in the assessment of high grade prostate carcinoma in patients with elevated PSA: a single-institution experience of 356 patients. Eur J Radiol 2011;77:340-345. 